\title{
Enhancement of Anticorrosive Performance of Renewable Cardanol Based Polyurethane Coatings by Incorporating Magnetic Hydroxyapatite Nanoparticles
}

\author{
Afzal Haq Asif ( $\square$ afzalhaqasif@gmail.com ) \\ King Faisal University \\ Mahendra s Mahajan \\ Kavayitri Bahinabai Chaudhari North Maharashtra University \\ Nagaraja Sreeharsha \\ King Faisal University \\ Vikas Gite \\ Kavayitri Bahinabai Chaudhari North Maharashtra University \\ Bandar Dhubiab \\ King Faisal University
}

Feroze Kaliyadan

King Faisal University

Shivakumar H Nanjappa

KLE University

Girish Meravanigeg

King Faisal University

Dalal Mishary Aleyadhy

King Faisal University

\section{Research Article}

Keywords: Cardanol, hydroxyapatite, nanocomposite, anticorrosive coatings, polyurethane, renewable materials

Posted Date: June 1st, 2021

DOI: https://doi.org/10.21203/rs.3.rs-526162/v1

License: (c) (i) This work is licensed under a Creative Commons Attribution 4.0 International License. Read Full License 
Version of Record: A version of this preprint was published at Materials on March 20th, 2022. See the published version at https://doi.org/10.3390/ma15062308. 


\section{Abstract}

The present investigation demonstrates renewable cardanol based polyol for the formulation of nanocomposite polyurethane (PU) coatings. The functional and structural features of cardanol polyol and nanoparticles were studied by FT-IR and ${ }^{1} \mathrm{H}$ NMR spectroscopic techniques. The magnetic hydroxyapatite nanoparticles (MHAP) were dispersed in PU formulations to develop nanocomposite anticorrosive coatings. The amount of MHAP in PU formulations was varied from 1-5\%, increase the percentage of MHAP increases the anticorrosive performance as examined by immersion and electrochemical methods. The nanocomposite PU coatings shows good coating properties viz., gloss, pencil hardness, flexibility, cross-cut adhesion and chemical resistance. Additionally, the coatings also studied for surface morphology, wetting, and thermal properties by scanning electron microscope (SEM), contact angle, and thermogravimetric analysis (TGA), respectively. The hydrophobic nature of PU coatings increased by addition of MHAP and optimum result $\left(105^{\circ}\right)$ was observed in $3 \%$ loading. The developed coatings revealed hydrophobic nature with excellent anticorrosive performance.

\section{Highlights}

1. Renewable cardanol was used to synthesis Mannish type polyol by solventless system for the development of bio-based polyurethane coatings.

2. Polyurethane anticorrsive nanocomposite coatings were prepared by incorporating a varied percentage of magnetic hydroxyapatite nanoparticles (MHAP).

3. Anticorrosive property of PU coatings was increased by increasing the percentage of MHAP as tested by immersion and electrochemical methods.

4. Addition of MHAP, increased hydrophobicity as estimated by contact angle.

\section{Introduction}

Corrosion is a process in which metal articles get damaged that can be from automobile, construction, aerospace, marines, and industrial sectors. Thus, metal corrosion has appeared as a big problem and results to inured massive losses to economy and human health. ${ }^{1-3}$ Anticorrosive paints and coatings based on synthetic polymeric resins are used to minimize such types of losses and to improve life span of various metal items. However, maximum polymeric resins used in the present paints and coatings are of petroleum origin. Depletion of petroleum sources and fluctuations in their prices made it necessary to find out some new alternatives such as renewable, readily available, and eco-friendly polymeric materials. Renewable materials including carbohydrates, lipids, vegetable oils, cardanol, eugenol, etc. have been explored to use in the preparation of monomers and polymers such as alkyd, epoxy, polyurethane, polyesters, polyacrylates, phenol formaldehyde resin, benzoxazines, etc. ${ }^{4-7}$ The resultant renewable source based polymers have found applications in the different fields such as coatings, composites, microencapsulation, reactive diluents, foams, and so on. Among all the renewable materials, cardanol have fascinated the researchers due to its unique chemical structure and possible chemical modifications 
through availability of reactive sites such as phenolic hydroxyl group, aromatic ring, and long aliphatic carbon chain with unsaturation. Aromatic ring provides chemical and thermal resistances, while hydroxyl group gives good adhesion. A long aliphatic carbon chain provides good flexibility, excellent water resistance, and anticorrosive properties.

Over a past decades, nanocomposite polymer coatings have been used to improve the corrosion, thermal, and mechanical properties of the coating formulations. They are developed from the nano-size fillers and polymeric resins. The polymeric resin helps to hold the nano-filler in the matrix that works as a reinforcing material or improves physico-mechanical properties of the composites. ${ }^{8,9}$ Various types of nano-size fillers such as $\mathrm{SiO}_{2},{ }^{10} \mathrm{ZnO},{ }^{11} \mathrm{TiO}_{2},{ }^{12} \mathrm{Fe}_{2} \mathrm{O}_{3},{ }^{13} \mathrm{ZrO}_{2},{ }^{14} \mathrm{Al}_{2} \mathrm{O}_{3},{ }^{15} \mathrm{~V}_{2} \mathrm{O}_{5},{ }^{16}$ graphene, ${ }^{17}$ and others. ${ }^{18}$ have been used in coating matrix for desired applications like improvement of adhesion, gloss, corrosion, scratch, thermal and antibacterial resistances. The main purpose for nanoparticle incorporation in the coating formulation is to enhance the physico-chemical as well as corrosion resistance properties of metal samples. Additionally, use of corrosion inhibitor is also possible based on precursors used in the formulation of coatings, thickness, and adhesion towards the metal surface. ${ }^{19}$ The protective organic/inorganic hybrid composite coatings are prepared by addition of magnetic hydroxyapatite nanoparticle (MHAP) as a reinforcing agent. Presence of MHAP has enhanced the coating properties such as chemical, wetting, and corrosion resistances.Previous reports are available on use of hydroxyapatite (HAP) for bone tissue engineering, controlled drug delivery, and as a filler for composites coatings. Even HAP modified with silver was used in the formulation of antibacterial composite coatings. ${ }^{20}$ Additionally, magnetically modified HAP was utilized in the removal of heavy metals such as

uranium (VI) ${ }^{21}$ lead ion, ${ }^{22}$ cadmium (II), ${ }^{23}$ copper, nickel, ${ }^{24}$ and other pollutants for the water. ${ }^{25}$ As per the literature, till today MHAP has not been used in the designing of anticorrosive coatings for the metal protection.

In the present experimental work, cardanol based Mannich polyol have been synthesized to obtain PU of renewable source based. Structural features of the prepared resin were confirmed by the end group analysis as well as by spectroscopic methods. Simultaneously, the magnetic hydroxyapatite nanoparticles were prepared and modified for their magnetic properties in order to improve anticorrosion properties of the PU coatings on mixing with polyol and further treatment with hexamethylene diisocyanate. The prepared PU composite coatings were tested for their physico-chemical and anticorrosive properties.

\section{Experimental}

\subsection{Materials}

Cardanol was provided as a gift sample by Polymer Division of Atul Ltd., India. Hexamethylene diisocyanate $(\mathrm{HDI})$, diethanolamine, and dibutyltin dilaurate (DBTDL) were purchased from Sigma Aldrich, India. Ferrous chloride tetrahydrate, ferric chloride, potassium hydroxide, calcium nitrate 
tetrahydrate, diammonium hydrogen phosphate, and xylene, were purchased from Loba Chemie, India. All the chemical used as such without any purification.

\subsection{Synthesis of cardanol based Mannich polyol}

Synthesis of cardanol Mannich polyol (CMP) was based on our previously reported method. ${ }^{26}$ In the first step, the formation of oxazolidine was done on reacting diethanolamine $(0.2 \mathrm{M})$ with formaldehyde $(0.2$ $\mathrm{M})$ in three-necked flask equipped with a magnetic stirrer, condenser, and thermometer. The reaction mixture was heated at $65^{\circ} \mathrm{C}$ for $2 \mathrm{~h}$ followed by distilling water off reaction to form oxazolidine intermediate. Thereafter, cardanol $(0.066 \mathrm{M})$ was added dropwise in the reaction mixture for $30 \mathrm{~min}$ and the reaction was maintained to $95^{\circ} \mathrm{C}$ for $4 \mathrm{~h}$. The progress of the reaction was checked by conducting thin layer chromatography (TLC) in ethyl acetate: hexane (20:80) system. Finally, the deep reddish coloured liquid of cardanol polyol was formed. The reaction for synthesis of CMP is given in the Scheme1.

\subsection{Synthesis of magnetic hydroxyapatite nanoparticle}

Magnetic hydroxyapatite nanoparticles were synthesised according to the literature procedure with some modification. ${ }^{27,28}$ In the typical process, ferrous chloride tetrahydrate $(1.85 \mathrm{mM})$ and ferric chloride (3.78 $\mathrm{mM}$ ) were dissolved in $30 \mathrm{~mL}$ DI water taken in $250 \mathrm{~mL}$ round bottom flask under stirring at $500 \mathrm{rpm}$ in the presence of nitrogen atmosphere. After $1 \mathrm{~h}$, the complete clear orange colour solution was formed. Then, $10 \mathrm{~mL} 30 \%$ ammonia solution was added dropwise into the reaction mixture and kept at $70{ }^{\circ} \mathrm{C}$ temperature for $1 \mathrm{~h}$ to form black colour iron oxide nanoparticles. The entire synthesized iron oxide nanoparticles were well dispersed in a solution of calcium nitrate tetrahydrate $(33.7 \mathrm{mM})$ and diammonium hydrogen phosphate $(20 \mathrm{mM})$ prepared in $250 \mathrm{~mL}$ beaker containing $50 \mathrm{~mL}$ DI water. Afterward, the $\mathrm{pH}$ of the solution was adjusted to 11 using ammonia solution. This mixture was stirred for $3 \mathrm{~h}$ at $90{ }^{\circ} \mathrm{C}$ temperature under nitrogen atmosphere. Milky white particles formed were centrifuged and washed with water and ethanol to remove impurities. The resulting particles were magnetically separated from the medium using local magnet and dried in an oven at $70^{\circ} \mathrm{C}$. Then, the particles were grinded in a mortar pestle and filtered using 150 mesh size sieved for their uniform size and utilized for further application.

\subsection{Formulation of polyurethane nano-composite coatings}

Mild steel (MS) panels were used as substrate for application of PU nanocomposites coatings. The MS substrate was pre-treated with sandpaper, degreased with acetone, and dried in an oven for $20 \mathrm{~min}$. The required quantity of MHAP of $0,1,2,3,4$ and $5 \mathrm{wt}$. \% and CMP were dispersed into the xylene with stirring. Then, the calculated amount of hexamethylene diisocyanate (HDI) in the ratio of NCO:OH 1.2:1 and DBTDL as a catalyst were added into the above mixture. After achieving desired viscosity to the resultant formulation, it was applied by brush on pre-treated mild steel (MS) panels of $4 \times 6$-inch ${ }^{2}$ dimension. The prepared coating panels were allowed to cure at room temperature for $48 \mathrm{~h}$. The prepared 
samples were coded as CMPU, CMPU-1, CMPU-2 CMPU-3, CMPU-4, and CMPU-5 based on the amount of MHAP. The schematic of PUs preparation reaction is represented in the Scheme-2.

\section{Characterisation Of Materials}

\subsection{End group analysis}

Hydroxy functionality is most important parameter in the development of polyurethane. They are deciding the actual quantity of diisocyanates for solid film development in the final crosslinked structure of PUs. it was determined by experimentally by following the ASTM D 6342-12 methods.

\subsection{Structural analysis}

Transformation of functional group of cardanol to cardanol mannich polyol and structural confirmation were determined by recording FT-IR spectra on a Perkin Elmer-1750 in the range between $4000-400 \mathrm{~cm}^{-}$ ${ }^{1}$ and ${ }^{1} \mathrm{H}$ NMR spectroscopic techniques on a Bruker Avance- $400 \mathrm{MHz}$ spectrometer in deuterated $\mathrm{CDCl}_{3}$ as a solvent and TMS as an internal standard.

\subsection{Testing properties of coatings}

\subsubsection{Gloss Test}

The lustrous property of PU coatings was investigated using a digital gloss meter (Model BYK Additives and instruments, Germany) at an angle of $60^{\circ}$. For the testing, 10 different positions on the surface of coated MS panels were considered and their average value was recorded as a final gloss of PU coatings.

\subsubsection{Adhesion Test}

Adhesion of developed coatings to the mild steel surface was checked using a cross cut adhesion tester (model no. 107, Elcometer U.K.) as per the method ASTM D-3359-02. The tester tool box contained a die of parallel sets of 10 blades, adhesive tape (Scotch brand 810 magic tape), brush and lens. Initially the coated surface was rapidly crashed two times in $90^{0}$ to each other with the help of blade and smoothly cleaned using brush. Then, the adhesive tape was pressed on the crashed surface and pulled within $60 \mathrm{~S}$ at $180^{\circ}$ angle. Finally, the visual confirmation of percentage of squares adhered on the surface of adhesive tape form cross cut MS panel with respect to the total initial number of squares were considered for calculating adhesion of the coatings with metal substrate.

\subsubsection{Pencil hardness}

Hardness of PU coated samples were determined by using pencil hardness tester (BYK Additive \& Instrument) as per the ASTM D-3363 standards. The test was carried by pushing pencils on the coated samples at an angle of $45^{0}$ and repeated at fresh place every time until the pencils formed scratches on the surface of coatings. 


\subsubsection{Flexibility}

The flexibility of prepared coating samples was tested by a Conical Mandrel Instrument (Raj Scientific Co., Mumbai, India) in the range of $45-180^{\circ}$ angle.

\subsubsection{Contact angle}

Surface hydrophobicity of PU coating samples were determined using a Contact Angle Tensiometer, Model 200 standard Goniometer (p/n 200-F4) of Rame-hart Instrument Co., USA. The test samples were fitted on the stage of the equipment and liquid drop of deionized water with constant volume (Approx. 3-5 $\mu \mathrm{dm}^{3}$ ) was dropped on the surface of the PU coated sample using a micro-syringe (Theremo Scientific Gilmont Micrometer Syringe Model- GS-1200). All the measurements were taken at room temperature and average of 10 times was considered for reporting.

\subsubsection{Corrosion performance}

Corrosion performance of developed PU coatings were examined by immersion and electrochemical testings.

Immersion study was used to examine the corrosion performance by deeping the uncoated and PU coated MS samples in $3.5 \% \mathrm{NaCl}$ aqueous solution for 7 days. After testing the coated samples were compared with control for change in gloss, deterioration, cracking, and partial or complete removal of film from the surface. The result was in the form of captured images of both before and after testing of all the samples.

The corrosion performance of prepared PU coatings was also checked by electrochemical testing. The analysis was done by an Auto lab PGSTAT30 potentiostat instrument and all analysis was carried at room temperature in an aqueous $3.5 \mathrm{wt} . \% \mathrm{NaCl}$ solution. The analysis comprises tree electrodes viz. platinum wire as a working, calomel and coated MS strips as counter and working electrodes. The area of the coated panels exposed to the test solution was $1 \times 0.5 \mathrm{~cm}^{2}$ in all the cases and the range of testing current potential was kept in between -1 to $+1 \mathrm{~V}$ at the scan rate of $0.01 \mathrm{~V} / \mathrm{s}$.

\subsubsection{Chemical resistance}

The chemical resistance was checked by dipping the coatings into aqueous acid and alkali solutions, water, and xylene as an organic solvent in 7 days. Chemical resistance of PU coatings also checked by ethyl methyl ketone (MEK) rub test as per the ASTM D-5402. The test was carried by rubbing the MEK wet cotton cloth on the surface of coated samples. The maximum number of double rubs at which the coatings was removed from the surface or passed 200 rubs that considered as final result values

\subsubsection{Thermal property}


Thermal property of prepared PU films was studied in the range of 40 to $800^{\circ} \mathrm{C}$ using a thermogravimetric analyser (TGA), Perkin Elmer TGA-4000 (USA). All the PU films were measured at heating rate of $10^{\circ} \mathrm{C}$ per min under an inert nitrogen atmosphere at the flow rate of $20 \mathrm{~mL} / \mathrm{min}$.

\subsubsection{Surface morphology}

Surface morphology of the prepared PU films was observed under a scanning electron microscope (SEM) (FESEM, S-4800, Hitachi High Technologies Corp). The accelerating voltage was in the range of 0.5 to 30 $\mathrm{kV}$ and with emission current at about $10 \mu \mathrm{A}$.

\section{Results And Discussion}

\subsection{Formation of cardanol based polyol}

Renewable cardanol based polyol was synthesised by the Mannich condensation of cardanol, diethanolamine, and formaldehyde. Overall process for the synthesis of CMP was considered as ecofriendly due to its solvent-less nature. Initially, diethanolamine and formaldehyde were condensed together to form the oxazolidine intermediate. ${ }^{26}$ Oxazolidine is present in the equilibrium with cyclic and open chain forms. The open chain form is an iminium cation, which is the well-known intermediate of Mannich reactions. ${ }^{29-31}$ In the presence of base (i.e. oxazolidine and tertiary amine), cardanol dissociates in the cardonalate anion with the negative charge circulated at equilibrium in resonance hybrids at oxygen and at ortho and para positions of aromatic ring. Finally, it results into a substituted product at ortho and para positions of the phenolic hydroxyl group of cardanol. The mechanism for the synthesis of CMP is presented in the Figure-1.

Structural confirmation of the cardanol based polyol was done by FT-IR and ${ }^{1} \mathrm{H}$ NMR spectroscopies. The FT-IR spectrum of CMP is graphically represented in the Figure-2. The stretching vibration band at 3371 $\mathrm{cm}^{-1}$ was related to the $-\mathrm{OH}$ group present in the cardanol and CMP. Absorption bands associated with vibration of symmetric and asymmetric $-\mathrm{CH}_{2}$ group were seen in between $2854-2924 \mathrm{~cm}^{-1}$, while aromatic $-\mathrm{C}-\mathrm{H}$ stretching vibration was observed at $3009 \mathrm{~cm}^{-1}$. The band at $1651 \mathrm{~cm}^{-1}$ was arise due to the presence of $-\mathrm{C}=\mathrm{C}$ - bond present in the CMP and cardanol. The new broad peak observed in the FT-IR spectra of CMP at $1041 \mathrm{~cm}^{-1}$ for $-\mathrm{C}-\mathrm{N}$ - stretching confirmed the reaction of oxazolidine with cardanol formed cardanol Mannich polyol.

Additionally, structural confirmation of cardanol and CMP were carried by ${ }^{1} \mathrm{H}$ NMR and their spectra shown in the Figure-3. In the spectrum of cardanol, the chemical shift of terminal methylene proton was appeared at $0.9 \mathrm{ppm}$ and all $-\mathrm{CH}_{2}$ - linkages were observed at 1.25-1.5 ppm. The peaks found between 5.03-5.46 ppm were related to the protons of $-\mathrm{C}=\mathrm{C}-$, while the peaks at 2.03 and $2.55 \mathrm{ppm}$ corresponded to the $-\mathrm{CH}_{2}$ - protons adjacent to the unsaturation and aromatic ring, respectively. The peak at 4.6 and 6.68$7.17 \mathrm{ppm}$ were related to the phenolic protons and aromatic benzene ring. In the spectrum of CMP, new chemical shift was observed at 2.35 and $3.7 \mathrm{ppm}$, which were corresponded to the hydroxy and 
methylene protons present in between the nitrogen atom and phenolic aromatic ring, respectively. ${ }^{29}$ The appearance of these protons peak in the CMP spectrum evidenced happening of the reaction between oxazolidine with cardanol.

\subsection{FT-IR of magnetic hydroxyapatite nanoparticles}

FT-IR spectrum of MHAP nanoparticles is represented in the Figure-4. The broad absorption band at 3570 $\mathrm{cm}^{-1}$ was related to $-\mathrm{OH}$ bending vibration. The stretching vibration of carbonyl were observed at 1458 , and $871 \mathrm{~cm}^{-1}$ while, phosphate group shown absorption at 1035 and $630 \mathrm{~cm}^{-1} .21,32,33$ The Fe-O bond stretching vibration bands were occurred at 1619 and $530 \mathrm{~cm}^{-1}$. It proved that MHAP nanoparticles were successfully formed.

\subsection{Magnetic behaviour of MHAP nanoparticles}

The magnetic property of the nanoparticles was tested by a simple magnet test. For this purpose, the synthesized nanoparticles were suspended in a water-ethanol solution and sonicated for 5 min to form complete suspension of nanoparticles (Figure-5 a). Afterward, the magnet was connected to bottles as shown in the Figure-5 $\mathbf{b}$. In a few seconds, all the nanoparticles were attracted towards the magnet, which concluded that the synthesized particles were with magnetic behaviour.

\subsection{Coating properties}

Determining the properties of coating is important in order to find out the suitability the coating formulations. The determined results of coating properties are represented in the Table-1. The gloss of all the coated samples was observed in the range of 73 to 121. Gloss value of pristine sample was more than all nanocomposite coatings because incorporation of MHAP nanoparticles would have increased opacity as well as roughness of the coatings surface. Thus, as the percentage of MHAP was increased in coating formulations, it decreased the gloss. All the coatings showed $100 \%$ adhesion towards metal surface as not a single block was removed from the area of the scratched surface. Hence, it concludes that the formulated coatings are with excellent adhesion to the metal surface. The MHAP nanoparticles incorporated coatings were not scratched to the level of a $5 \mathrm{H}$-grade pencil. The coatings containing 4 and $5 \%$ MHAP nanoparticles presented better pencil hardness $(5 \mathrm{H})$ than other coating samples. It may be due to the magnetic nature of MHAP nanoparticles that might have resulted in high interactive forces between metal surfaces and the coating matrix. All the coating samples passed the flexibility test that can offer prevention of crack formation. Addition to that the chemical resistance of all the prepared coatings was checked using methyl ethyl ketone rub test. There was no any defect found such as film removed from the surface, crack formation, and changing colour of coating on the surface up to 200 double rubs. Finally, on the basis of all the coating properties, one can say that the developed coatings are suitable for the coatings on metal surfaces.

\section{Table-1: Coating properties of prepared PUs coatings}




\begin{tabular}{|llllll|}
\hline $\begin{array}{l}\text { PUs } \\
\text { code }\end{array}$ & $\begin{array}{l}\text { Gloss } \\
60^{\circ}\end{array}$ & $\begin{array}{l}\text { Cross-cut adhesion } \\
(\%)\end{array}$ & $\begin{array}{l}\text { Pencil } \\
\text { hardness }\end{array}$ & Flexibility & $\begin{array}{l}\text { MEK double rub } \\
\text { test }\end{array}$ \\
\hline MHPU-0 & 121 & 100 & $3 \mathrm{H}$ & Pass & 200 \\
\hline MHPU- & 96 & 100 & $3 \mathrm{H}$ & Pass & 200 \\
\hline MHPU-2 & 85 & 100 & $4 \mathrm{H}$ & Pass & 200 \\
\hline MHPU-3 & 84 & 100 & $4 \mathrm{H}$ & Pass & 200 \\
\hline MHPU-4 & 74 & 100 & $5 \mathrm{H}$ & Pass & 200 \\
\hline MHPU-5 & 73 & 100 & $5 \mathrm{H}$ & Pass & 200 \\
\hline
\end{tabular}

\subsection{Chemical resistance study}

Chemical resistance of the developed cardanol based nanocomposite coatings was studied in $5 \% \mathrm{HCl}$, and $5 \% \mathrm{NaOH}$ solutions, water and xylene as an organic solvent for 7 days. The obtained results of test are expressed in the Table-2 and captured images are given in the Figure-6.

Table-2. Chemical resistance of bared, CMPU, CMPU-1, CMPU-2, CMPU-3, CMPU-4, and CMPU-5

\begin{tabular}{|lllll|}
\hline Sample Code & Water & $\mathrm{HCl}$ & $\mathrm{NaOH}$ & Xylene \\
\hline Bared & F & F & F & F \\
\hline CMPU & B & D & A & A \\
\hline CMPU-1 & B & B & A & A \\
\hline CMPU-2 & C & C & A & A \\
\hline CMPU-3 & B & C & A & A \\
\hline CMPU-4 & B & B & A & A \\
\hline CMPU-5 & B & B & A & A \\
\hline
\end{tabular}

( $A=$ Not affected, $B=$ slight loss in gloss, $C=$ Change in colour and loss in gloss, $D=$ film partly removed $E=$ film completely removed $F=$ fully damaged)

The results clearly detected that the bared and MHAP nanoparticle added PU coating samples were totally damaged, film detached from surface, and shown loss in gloss in the water and acid media. On the other hand, PUs added with MHAP shown better resistance against those media with exception of only slight loss in gloss. These results indicated that the presence of MHAP plays role in increasing the adhesion of metal surface. Minor loss in gloss was noted to all the coatings in the alkali medium, while all the prepared coatings shown excellent results against solvent medium, which may be attributed to the 
good interaction between the MHAP and polyurethane matrix. Thus, all the composite coatings with MHAP shown better chemical resistance as compared to the pristine PU.

\subsection{Anticorrosive performance by immersion method}

Corrosion resistance of the prepared nanocomposite coatings was examined by deeping the coated and uncoated samples in $3.5 \% \mathrm{NaCl}$ solution. After the test, analysed samples were compared with control samples and captured images are given in the Figure-7. The bared sample fully corroded, as it does not cover PU coating layer and had direct contact with the corrosive medium. From the test results, it was revealed that the MHAP based nanocomposite coatings provide superior corrosion resistance as compared to the bared and without MHAP coatings. the presence of MHAP nanoparticles in the PU matrix provides a strong adhesion over the metal surface and act as a barrier between corrosive media and metal surface, which caused inhibition in the corrosive process.

\subsection{Anticorrosive study by electrochemical method}

Anticorrosive performance was also examined by measuring tafel plots of uncoated, coated, and MHAP added coating samples in $3.5 \% \mathrm{NaCl}$ solution. The tafel plots of all the PU samples are shown in the Figure-8. The plots were used to estimate corrosion potential $\left(\mathrm{E}_{\text {corr }}\right)$, corrosion current density $\left(\mathrm{I}_{\text {corr }}\right)$, polarization resistance (Rp), and corrosion rate (CR). Using Tafel extrapolation method based on the software Nova 1.8, values of these corrosion parameters were calculated and represented in the Table-3. Generally anticorrosive coatings are exhibiting higher $\mathrm{E}_{\text {corr }}$ and lower $\mathrm{I}_{\text {corr }}$ values corresponding to the lower corrosion rate and vice-versa. ${ }^{34,35}$ The MHAP nanoparticles added coatings showed lower I corr values and higher $\mathrm{E}_{\text {corr }}$ values than the blank and pristine (CMPU) coatings. As the percent loading of MHAP in formulations increased, it decreased the $I_{c o r r}$ values of the coatings because of increase in adherence of the coatings with the metal surface due to magnetic property of MHAP particles and formation of protective barrier between corrosive ions and metal substrate.

Table-3: Electrochemical corrosion measurement of bare, CMPU, CMPU-1, CMPU-2, CMPU-3, CMPU-4, and CMPU-5 coated samples. 


\begin{tabular}{|llllll|}
\hline $\begin{array}{l}\text { Sample } \\
\text { Code }\end{array}$ & $\begin{array}{l}E_{\text {corr }} \\
(\mathrm{mV})\end{array}$ & $\begin{array}{l}I_{\text {corr }} \\
(\mathrm{nA})\end{array}$ & $\begin{array}{l}\mathrm{Rp} \\
(\mathrm{k} \Omega)\end{array}$ & $\begin{array}{l}\text { Corrosion rate (CR) } \\
(\mathrm{mm} / \text { year) }\end{array}$ & $\begin{array}{l}\text { Inhibition } \\
\text { efficiency } \\
(\% \text { IE) }\end{array}$ \\
\hline $\begin{array}{l}\text { Bare } \\
\text { (Uncoated) }\end{array}$ & -656.47 & 968.44 & 4.929 & 0.0442 & 0.00 \\
\hline MHPU-0 & -618.24 & 528.12 & 8.994 & 0.00814 & 45.47 \\
\hline MHPU-1 & -602.31 & 479.09 & 8.954 & 0.00812 & 50.52 \\
\hline MHPU-2 & -544.68 & 465.71 & 10.343 & 0.00709 & 51.91 \\
\hline MHPU-3 & -554.76 & 372.97 & 23.280 & 0.005483 & 61.48 \\
\hline MHPU-4 & -547.84 & 345.10 & 16.059 & 0.00401 & 64.47 \\
\hline MHPU-5 & -535.07 & 181.35 & 116.520 & 0.000582 & 81.28 \\
\hline
\end{tabular}

Percent IE was determined from the values of corrosion current density of uncoated and coated samples. In general, higher the Icorr values lower is the inhibition efficiency to the coatings. The graphical presentation of all the coated and uncoated samples is shown in the Figure-9. The corrosion inhibition efficiency of MHAP added coating samples was far better than the blank and CMPU. Higher efficiency was obtained for the $5 \%$ loaded coating due to the well adhesion of PU formulation to the MS substrate. Additionally, the hydrophobic nature of the coatings might have helped to enhance the anticorrosive behaviour by restricting interaction between coatings and corrosive media.

The corrosion rate versus type of coatings is graphically represented in the Figure-10. Corrosion rate of all the PU coated samples was better than the uncoated one. Therefore, it confirmed that the prepared PU formulations acted as an obstacle for said medium to interact substrate and thus decreased the corrosion rate. From all the results, it can be concluded that the developed PU coatings were with good resistance against corrosion, which increased with increase in the percent loading of MHAP nanoparticles in coatings.

\subsection{Contact Angle}

Contact angle of the coated CMPU and all the MHAP embedded coated samples was measured to estimate the surface hydrophobicity and the results are shown in the Figure-11. From the result, it was observed that all the nanocomposite coated MS samples were more hydrophobic than the pristine coated sample. The contact angle of all the nanocomposite coatings was found to be more than $90^{\circ}$, which was much higher as compared to MHAP coatings $\left(87^{\circ}\right)$ without nanoparticles. Contact angle of the coating samples increased with increase in the amount of MHAP nanoparticles upto $3 \%$, beyond that declining the values of contact angle was seen. Overall, results of contact angle revealed hydrophobic nature to all the prepared nanocomposite PU coatings.

\subsection{Thermogravimetric Analysis}


Thermograms of all the prepared PU films are presented in the Figure-12. The thermal analysis showed three steps of thermal degradation in all the PU films. The first step of degradation was started in the range of $212-225^{\circ} \mathrm{C}$ and ended at $410-419^{\circ} \mathrm{C}$ with degradation result of $30-38 \%$ weight losses due to the breakdown of urethane groups in PUs. In the second step, degradation occurred in the range of 416$425^{\circ} \mathrm{C}$ and ended at $530-539^{\circ} \mathrm{C}$ with weight losses $35-43 \%$ due to the degradation of main backbone chain of PUs. The third step of degradation observed in the range of $534-536^{\circ} \mathrm{C}$ and completed at $643-$ $677^{\circ} \mathrm{C}$ with weight losses of $17-19 \%$ as a result of residual degradation. Thus, it can be stated that all the prepared composite coatings resulted with excellent thermal stability.

\subsection{Surface Morphology of MHAP Composite Coating}

The MHAP nanoparticles and their PU coatings were observed under a scanning electron microscope and the selected images are represented in the Figure-13. The morphology of MHAP nanoparticles showed irregular shape agglomers with an average size $38.64 \mathrm{~nm}$. The particles shown smooth surface and separated from each other. The CMPU appeared as a smooth surface as it does not contain MHAP as well as it was free from phase separation or presence of any voids. Images of MHAP incorporated coatings were also clear and homogeneous with absence of any type of phase separation or cracks over the surface. Therefore, it can be concluded that MHAP was properly dispersed in the PU formulation and interacted with matrix. Furthermore, all the coatings were free from the microcracks, voids, and phase separation.

\section{Conclusion}

Cardanol was used as a renewable phenol for the preparation of Mannich type polyol, which was further utilized in the formulation of PU nanocomposite coatings using various percentage of $\operatorname{MHAP}(1,2,3,4$, and $5 \%)$. The synthesised cardanol Mannich polyol was characterised for structural features by FT-IR and ${ }^{1} \mathrm{H}$ NMR spectroscopic techniques. MHAP was synthesised in the laboratory and characterized by FT-IR and SEM analysis. The developed PU nanocomposite coatings demonstrated good physco-chemical properties. The prepared coatings showed excellent anticorrosion and chemical resistance tests. The hydrophobic character of coatings increased upto $3 \%$ loading of MHAP beyond that it decreased as measured by contact angle test. All the coatings showed good thermal stability and smooth surface morphology as studied by TGA and SEM respectively.

\section{Declarations}

Conflicts of Interest The authors declare that there are no conflicts of interest.

Authors' Contributions All authors contributed to data analysis, drafting or revising the article, gave final approval of the version to be published, and agree to be accountable for all aspects of the work 
Acknowledgement This project has received funding from the Deanship of Scientific Research, King Faisal University, Al-Ahsa, Saudi Arabia. Grant Number-1811009

\section{References}

1. H. Montiel, J.A. Vílchez, J. Arnaldos, J. Casal, Historical analysis of accidents in the transportation of natural gas, J. Hazard. Mater. 1-3 (1996): 77-92. doi:10.1016/S0304-3894(96)01819-5.

2. S.J. Oh, D.C. Cook, H.E. Townsend, Atmospheric corrosion of different steels in marine, rural and industrial environments, Corros. Sci. 9 (1999): 1687-1702. doi:10.1016/S0010-938X(99)00005-0.

3. D. de la Fuente, I. Díaz, J. Simancas, B. Chico, M. Morcillo, Long-term atmospheric corrosion of mild steel, Corros. Sci. 2 (2011): 604-617. doi:10.1016/j.corsci.2010.10.007.

4. M.A.R. Meier, J.O. Metzger, U.S. Schubert, Plant oil renewable resources as green alternatives in polymer science, Chem. Soc. Rev. 11 (2007): 1788-1802. doi:10.1039/b703294c.

5. J.C. Khanderay, V. V. Gite, Fully biobased polyester polyols derived from renewable resources toward preparation of polyurethane and their application for coatings, J. Appl. Polym. Sci. 22 (2019): 47558. doi:10.1002/app.47558.

6. B. Lochab, S. Shukla, I.K. Varma, Naturally occurring phenolic sources: Monomers and polymers, RSC Adv. 42 (2014): 21712-21752. doi:10.1039/c4ra00181h.

7. C. Voirin, S. Caillol, N. V. Sadavarte, B. V. Tawade, B. Boutevin, P.P. Wadgaonkar, Functionalization of cardanol: Towards biobased polymers and additives, Polym. Chem. 9 (2014): 3142-3162. doi:10.1039/c3py01194a.

8. R. Vaithylingam, M.N.M. Ansari, R.A. Shanks, Recent Advances in Polyurethane-Based Nanocomposites: A Review, Polym. - Plast. Technol. Eng. 14 (2017): 1528-1541. doi:10.1080/03602559.2017.1280683.

9. H.D. Jirimali, B.C. Chaudhari, J.C. Khanderay, S.A. Joshi, V. Singh, A.M. Patil, V. V. Gite, Waste Eggshell-Derived Calcium Oxide and Nanohydroxyapatite Biomaterials for the Preparation of LLDPE Polymer Nanocomposite and Their Thermomechanical Study, Polym. - Plast. Technol. Eng. 8 (2018): 804-811. doi:10.1080/03602559.2017.1354221.

10. C. Zhou, X. Lu, Z. Xin, J. Liu, Y. Zhang, Polybenzoxazine/SiO2 nanocomposite coatings for corrosion protection of mild steel, Corros. Sci. 80 (2014): 269-275. doi:10.1016/j.corsci.2013.11.042.

11. H. Wang, X. Qiu, W. Liu, F. Fu, D. Yang, A novel Lignin/ZnO hybrid nanocomposite with excellent UVAbsorption ability and its application in transparent polyurethane coating, Ind. Eng. Chem. Res. 39 (2017): 11133-11141. doi:10.1021/acs.iecr.7b02425.

12. K. Kumar, P.K. Ghosh, A. Kumar, Improving mechanical and thermal properties of TiO2-epoxy nanocomposite, Compos. Part B Eng. 97 (2016): 353-360. doi:10.1016/j.compositesb.2016.04.080.

13. G. Liu, Y.F. Li, L.C. Zhou, B.O.N. Li, X.H.U. Men, X.Z. Li, Photo-heat transition of coatings derived from furfural resin and Fe 203 nanoparticles, High Perform. Polym. 4 (2005): 469-481. doi:10.1177/0954008305042474. 
14. S. Zhou, L. Wu, Phase separation and properties of UV-curable polyurethane/zirconia nanocomposite coatings, Macromol. Chem. Phys. (2008). doi:10.1002/macp.200800090.

15. Y. Wang, S. Lim, J.L. Luo, Z.H. Xu, Tribological and corrosion behaviors of Al203/polymer nanocomposite coatings, Wear. 11 (2008): 1170-1181. doi:10.1016/j.wear.2005.06.013.

16. H. Khatoon, S. Ahmad, Vanadium Pentoxide-Enwrapped Polydiphenylamine/Polyurethane Nanocomposite: High-Performance Anticorrosive Coating, ACS Appl. Mater. Interfaces. (2019). doi:10.1021/acsami.8b17861.

17. B. Yu, X. Wang, W. Xing, H. Yang, L. Song, Y. Hu, UV-curable functionalized graphene oxide/polyurethane acrylate nanocomposite coatings with enhanced thermal stability and mechanical properties, Ind. Eng. Chem. Res. (2012). doi:10.1021/ie3013852.

18. S. Mallakpour, M. Madani, A review of current coupling agents for modification of metal oxide nanoparticles, Prog. Org. Coatings. (2015). doi:10.1016/j.porgcoat.2015.05.023.

19. E.M. Fayyad, K.K. Sadasivuni, D. Ponnamma, M.A.A. Al-Maadeed, Oleic acid-grafted chitosan/graphene oxide composite coating for corrosion protection of carbon steel, Carbohydr. Polym. (2016). doi:10.1016/j.carbpol.2016.06.001.

20. C.K. Patil, H.D. Jirimali, J.S. Paradeshi, B.L. Chaudhari, V. V. Gite, Functional antimicrobial and anticorrosive polyurethane composite coatings from algae oil and silver doped egg shell hydroxyapatite for sustainable development, Prog. Org. Coatings. (2019). doi:10.1016/j.porgcoat.2018.11.002.

21. H.H. El-Maghrabi, A.A. Younes, A.R. Salem, K. Rabie, E. sayed El-shereafy, Magnetically modified hydroxyapatite nanoparticles for the removal of uranium (VI): Preparation, characterization and adsorption optimization, J. Hazard. Mater. (2019). doi:10.1016/j.jhazmat.2019.05.096.

22. F. Safatian, Z. Doago, M. Torabbeigi, H. Rahmani Shams, N. Ahadi, Lead ion removal from water by hydroxyapatite nanostructures synthesized from egg sells with microwave irradiation, Appl. Water Sci. (2019). doi:10.1007/s13201-019-0979-8.

23. X. Shen, X. Gao, W. Wei, Y. Zhang, Y. Zhang, L. Ma, H. Liu, R. Han, J. Lin, Combined performance of hydroxyapatite adsorption and magnetic separation processes for $\mathrm{Cd}(\mathrm{II})$ removal from aqueous solution, J. Dispers. Sci. Technol. (2019). doi:10.1080/01932691.2019.1703734.

24. D.N. Thanh, P. Novák, J. Vejpravova, H.N. Vu, J. Lederer, T. Munshi, Removal of copper and nickel from water using nanocomposite of magnetic hydroxyapatite nanorods, J. Magn. Magn. Mater. (2018). doi:10.1016/j.jmmm.2017.11.064.

25. Y. Wang, L. Hu, G. Zhang, T. Yan, L. Yan, Q. Wei, B. Du, Removal of Pb(II) and methylene blue from aqueous solution by magnetic hydroxyapatite-immobilized oxidized multi-walled carbon nanotubes, J. Colloid Interface Sci. (2017). doi:10.1016/j.jcis.2017.01.105.

26. M.S. Mahajan, P.P. Mahulikar, V. V. Gite, Eugenol based renewable polyols for development of $2 \mathrm{~K}$ anticorrosive polyurethane coatings, Prog. Org. Coatings. 148 (2020): 105826. doi:10.1016/j.porgcoat.2020.105826. 
27. V. Sarath Chandra, K. Elayaraja, K. Thanigai Arul, S. Ferraris, S. Spriano, M. Ferraris, K. Asokan, S. Narayana Kalkura, Synthesis of magnetic hydroxyapatite by hydrothermal-microwave technique: Dielectric, protein adsorption, blood compatibility and drug release studies, Ceram. Int. (2015). doi:10.1016/j.ceramint.2015.07.088.

28. S. Mondal, P. Manivasagan, S. Bharathiraja, M.S. Moorthy, V.T. Nguyen, H.H. Kim, S.Y. Nam, K.D. Lee, J. Oh, Hydroxyapatite coated iron oxide nanoparticles: A promising nanomaterial for magnetic hyperthermia cancer treatment, Nanomaterials. (2017). doi:10.3390/nano7120426.

29. M. Ionescu, X. Wan, N. Bilić, Z.S. Petrović, Polyols and Rigid Polyurethane Foams from Cashew Nut Shell Liquid, J. Polym. Environ. (2012). doi:10.1007/s10924-012-0467-9.

30. T.S. Gandhi, M.R. Patel, B.Z. Dholakiya, Synthesis of cashew Mannich polyol via a three step continuous route and development of PU rigid foams with mechanical, thermal and fire studies, Journal of Polymer Engineering. (2015). doi:10.1515/polyeng-2014-0176.

31. R.K. Gupta, M. Ionescu, X. Wan, D. Radojcic, Z.S. Petrovi囚, Synthesis of a Novel Limonene Based Mannich Polyol for Rigid Polyurethane Foams, J. Polym. Eng. (2015). doi:10.1007/s10924-015-07178.

32. K. Du, X. Liu, S. Li, L. Qiao, H. Ai, Synthesis of Cu2+ Chelated Cellulose/Magnetic Hydroxyapatite Particles Hybrid Beads and Their Potential for High Specific Adsorption of Histidine-Rich Proteins, ACS Sustain. Chem. Eng. (2018). doi:10.1021/acssuschemeng.8b01699.

33. Synthesis and characterization of nano-hydroxyapatite (n-HAP) using the wet chemical technique, Int. J. Phys. Sci. (2013). doi:10.5897/IJPS2013.3990.

34. J.C. Khanderay, V. V. Gite, Fully biobased polyester polyols derived from renewable resources toward preparation of polyurethane and their application for coatings, J. Appl. Polym. Sci. (2019). doi:10.1002/app.47558.

35. G.A. Phalak, D.M. Patil, S.T. Mhaske, Synthesis and characterization of thermally curable guaiacol based poly(benzoxazine-urethane) coating for corrosion protection on mild steel, Eur. Polym. J. (2017). doi:10.1016/j.eurpolymj.2016.12.030.

\section{Figures}




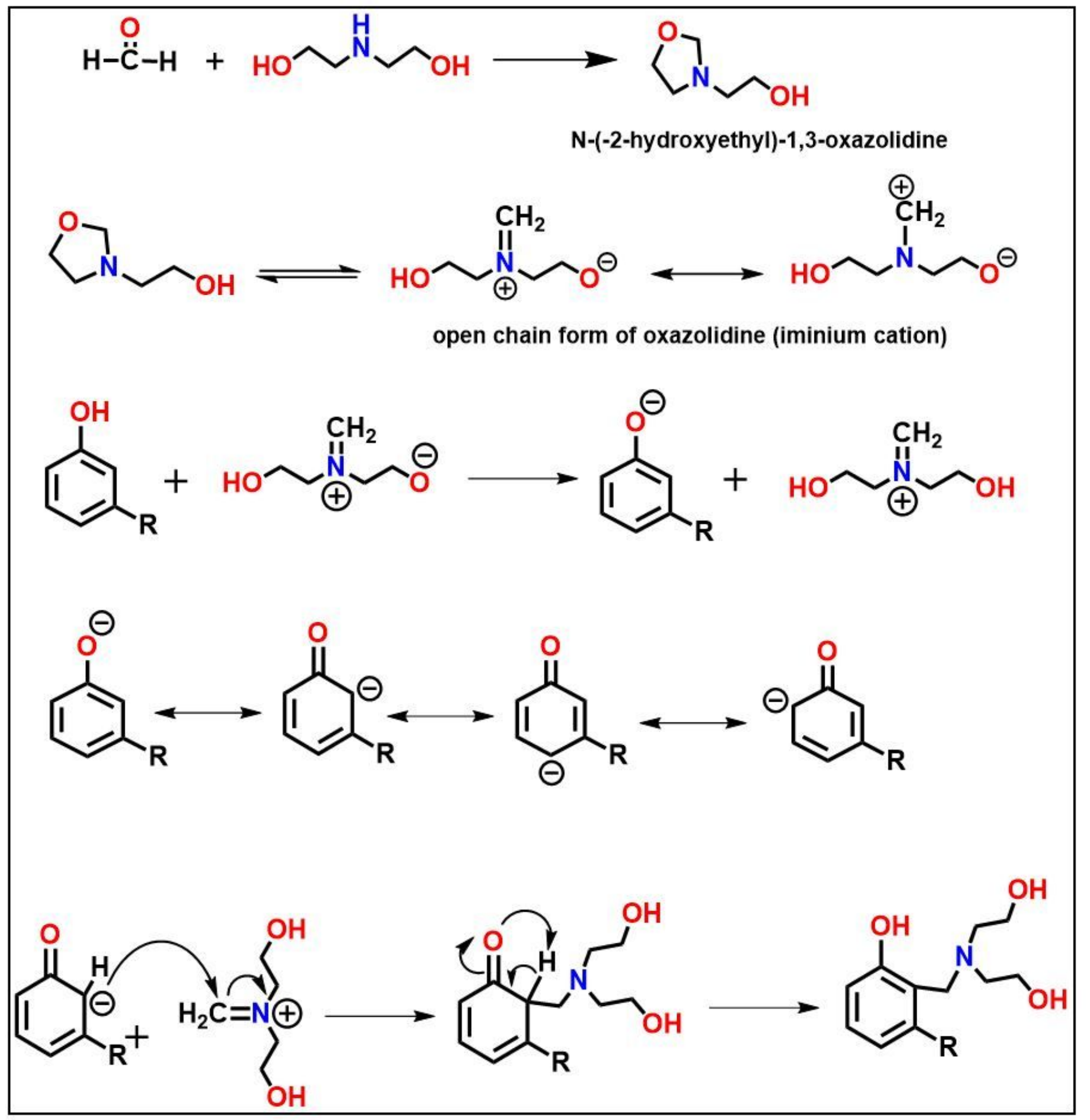

Figure 1

Mechanism for the formation of cardanol mannich polyol 


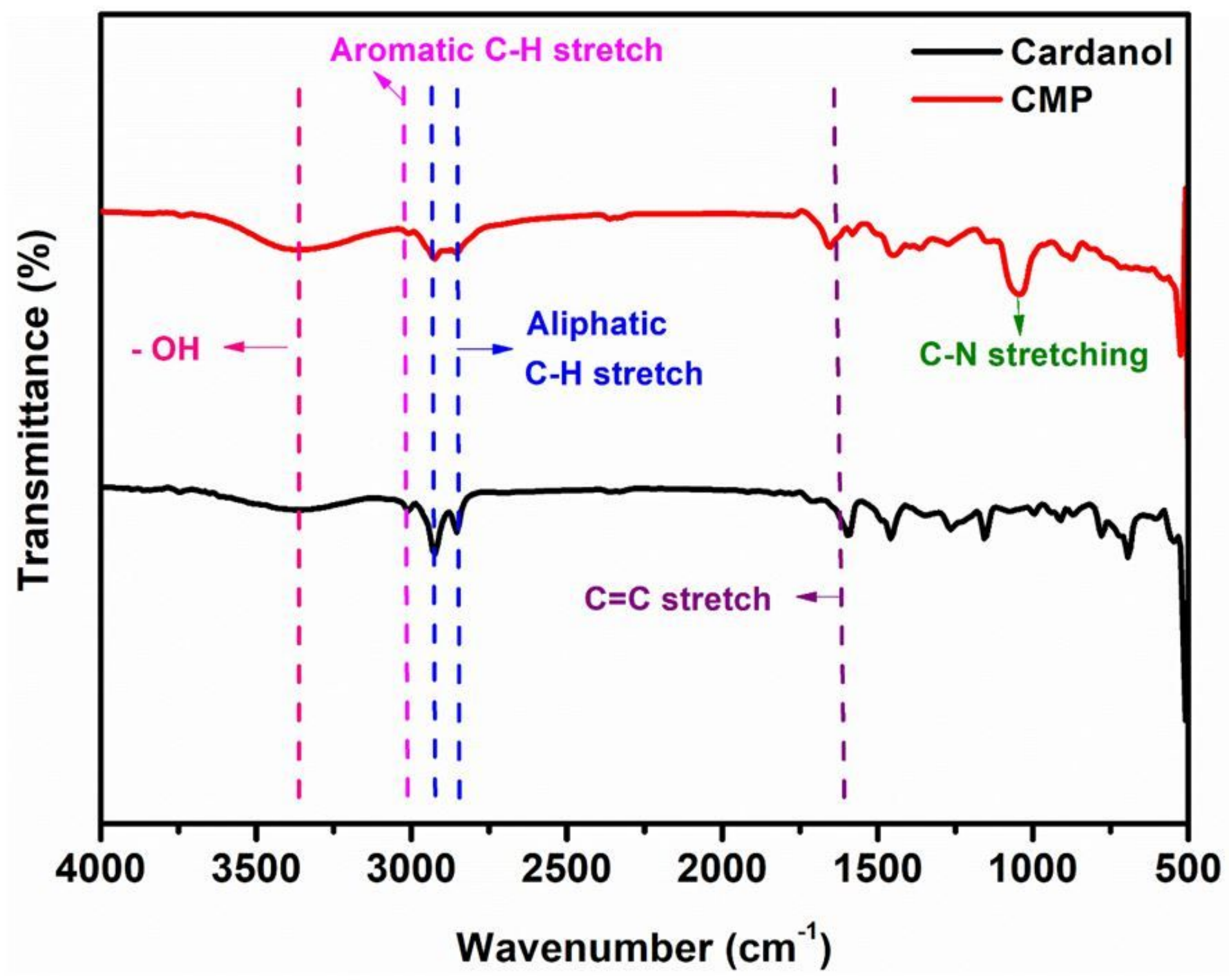

Figure 2

FT-IR spectra of cardanol and cardanol Mannich polyol 


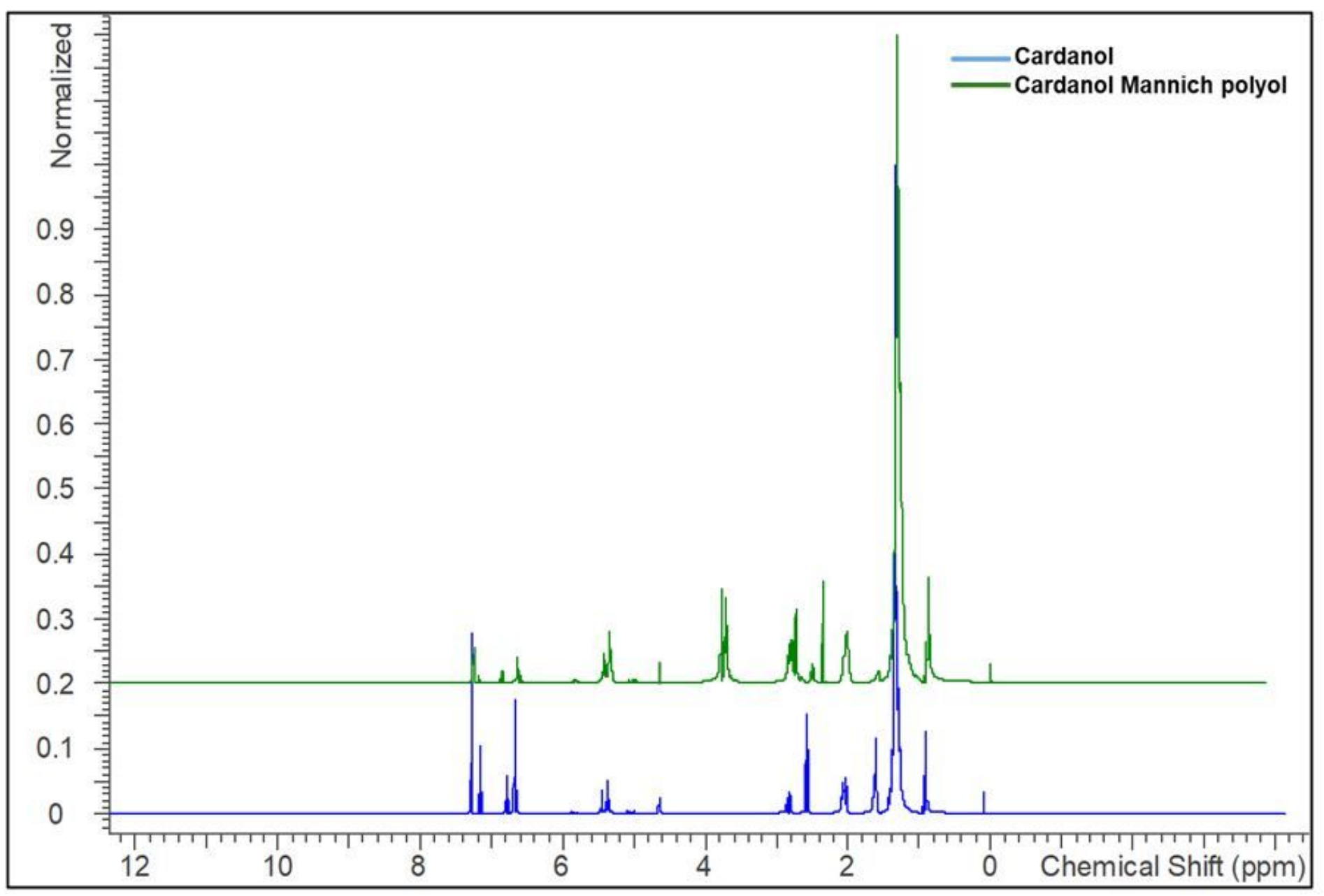

Figure 3

1H NMR of cardanol and cardanol Mannich polyol 


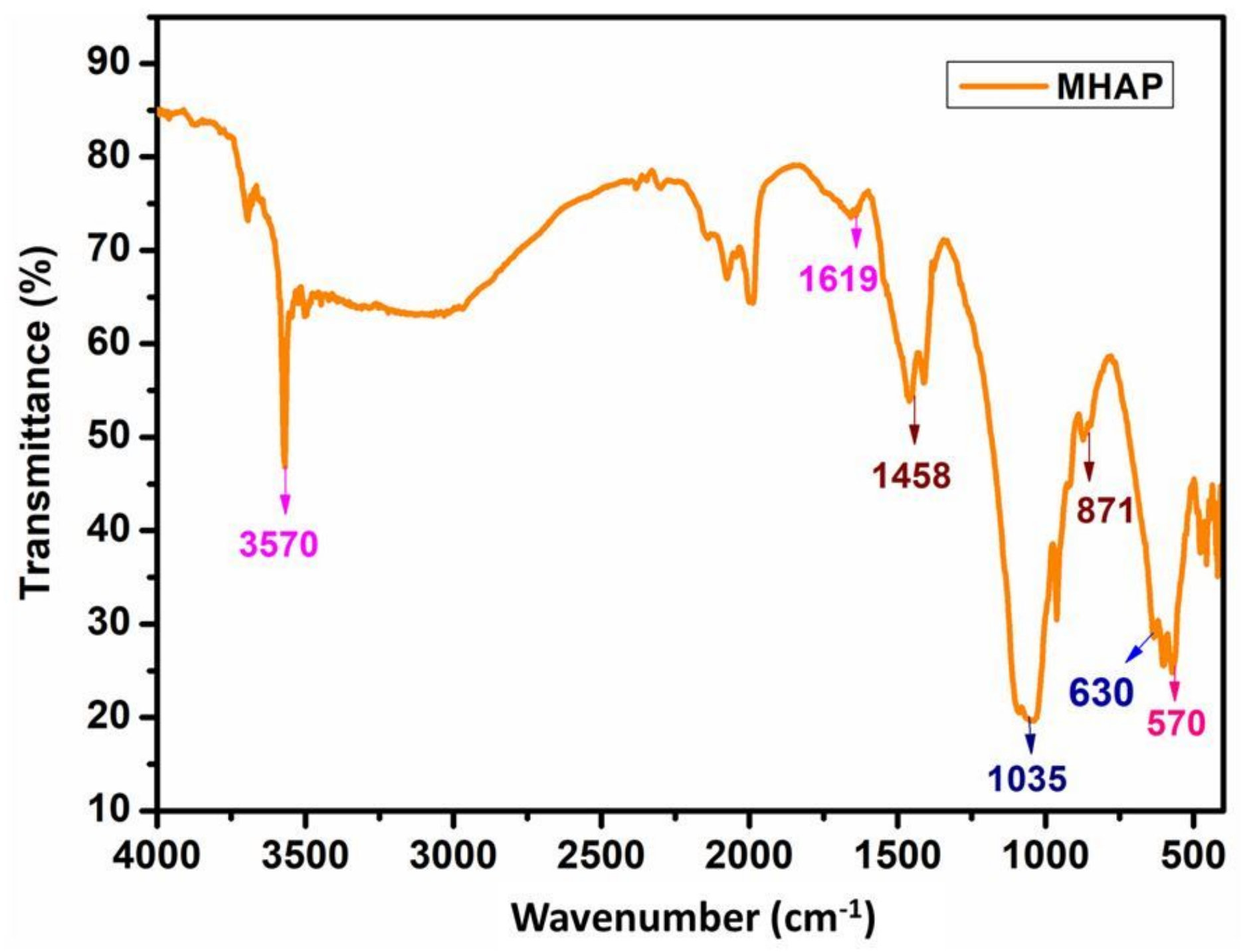

Figure 4

FT-IR spectrum of magnetic hydroxyapatite nanoparticles 


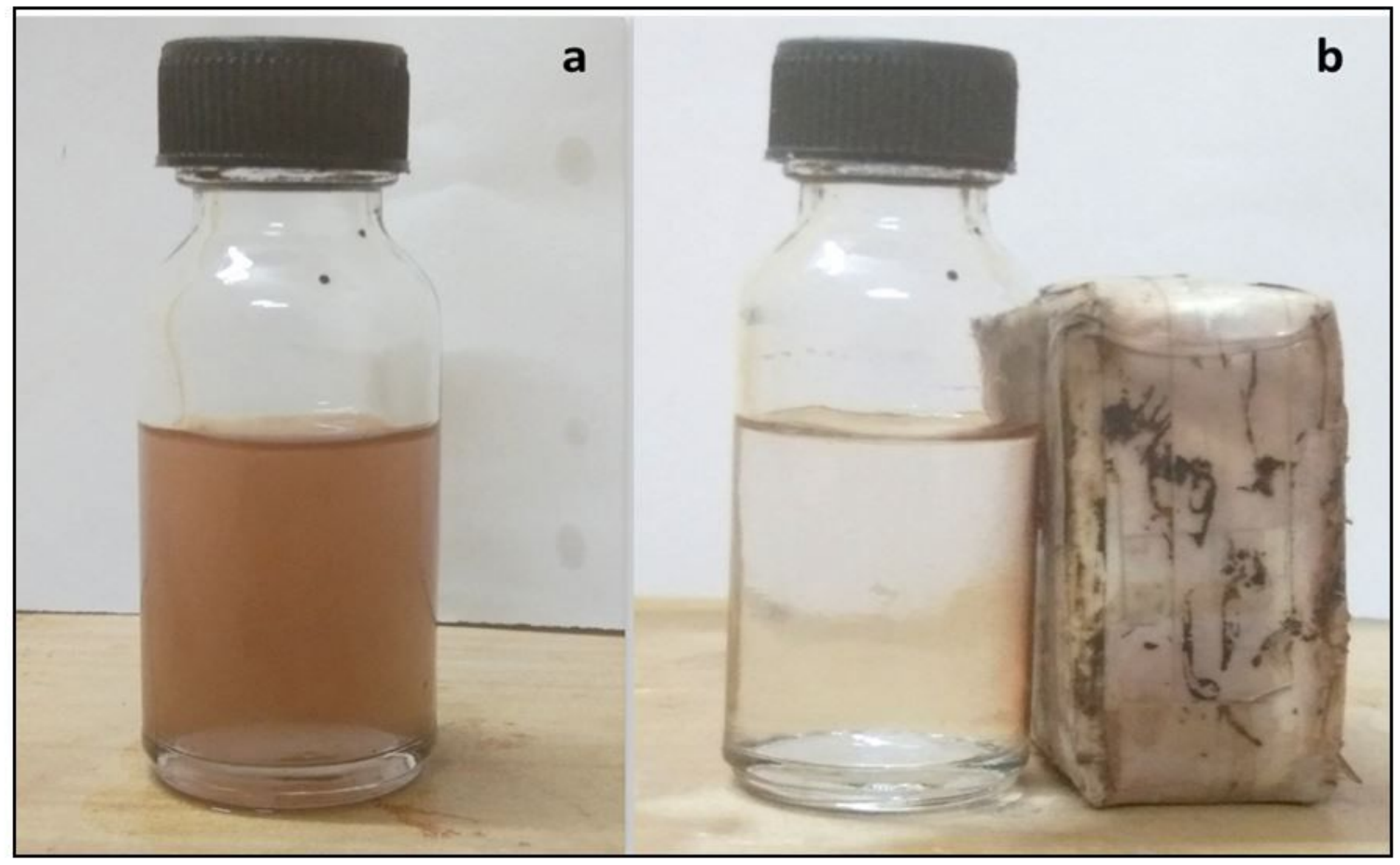

Figure 5

Magnetic behaviour of the MHAP nanoparticles (a) suspension of nanoparticles and b) MHAP nanoparticles attracted towards magnet 


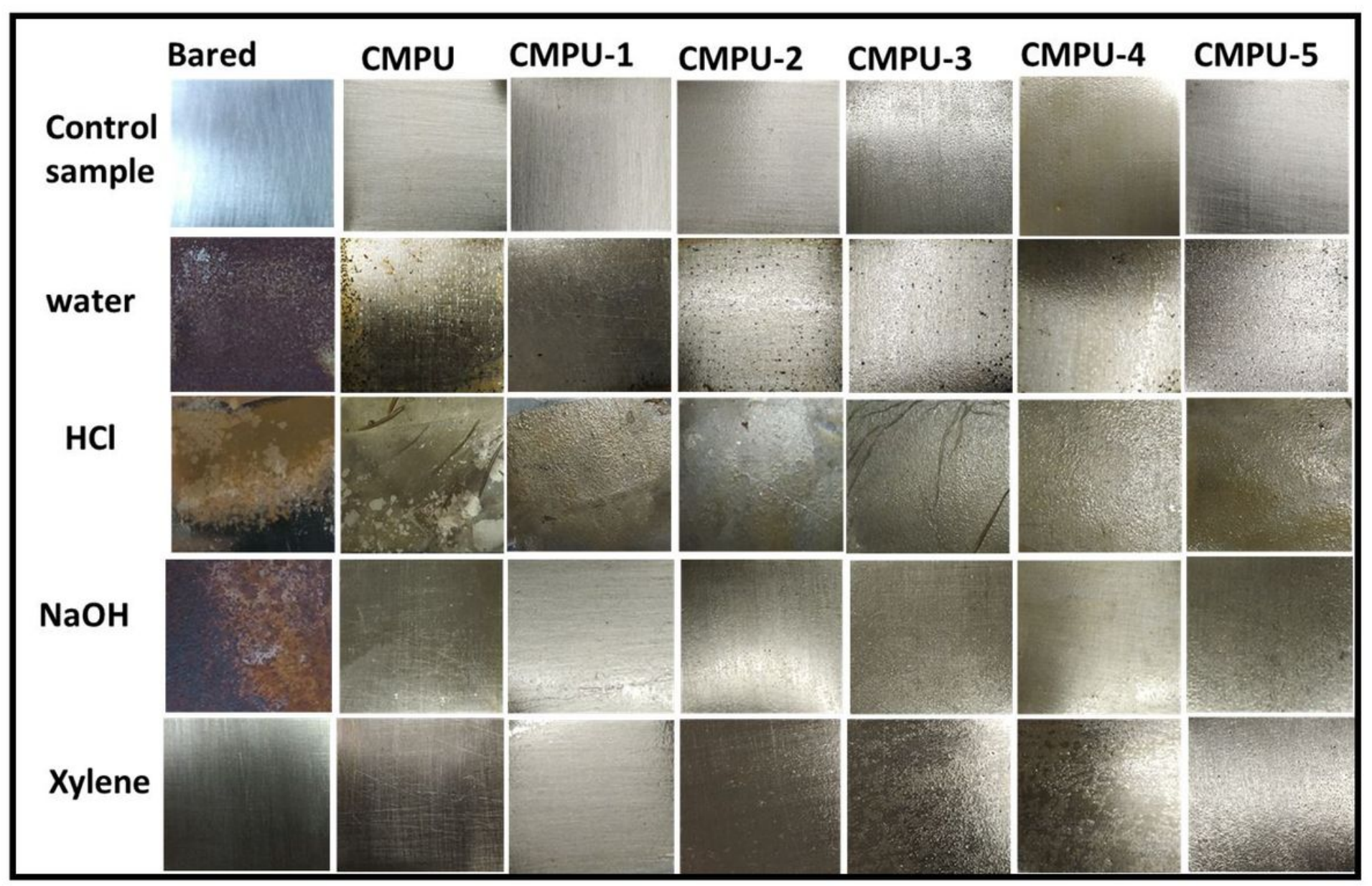

Figure 6

chemical resistance of bared and prepared PU coatings

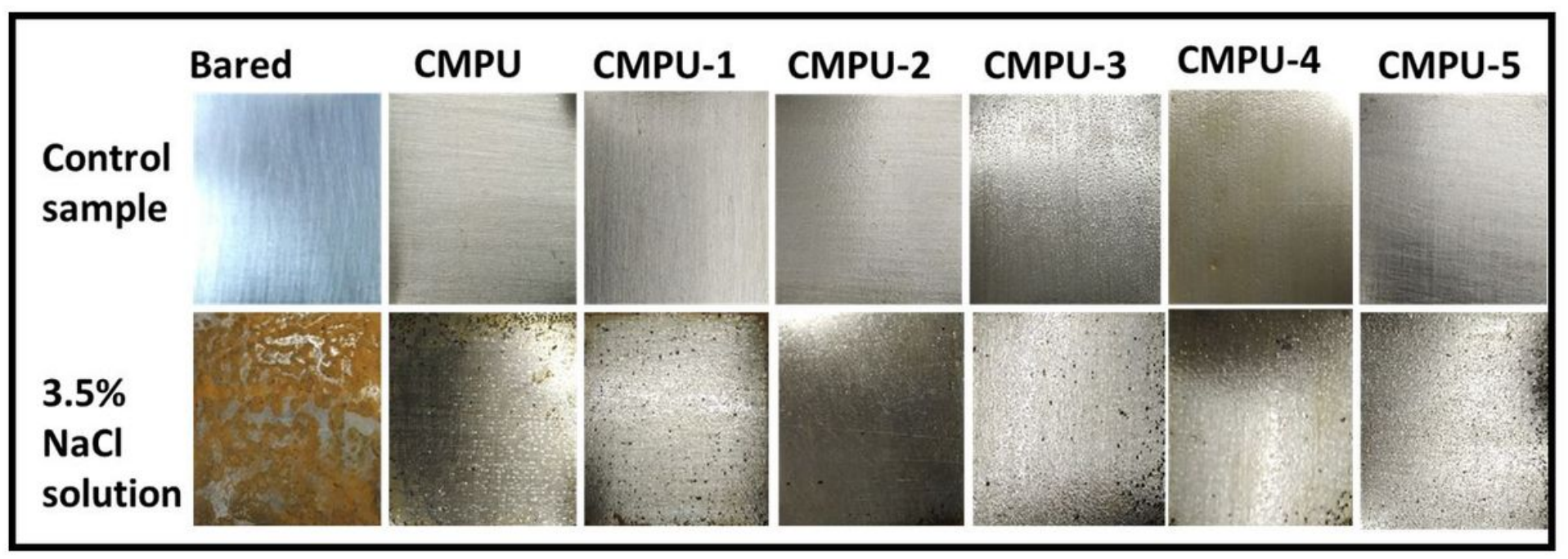

Figure 7

Anticorrosive performance of bared and prepare PU coatings 


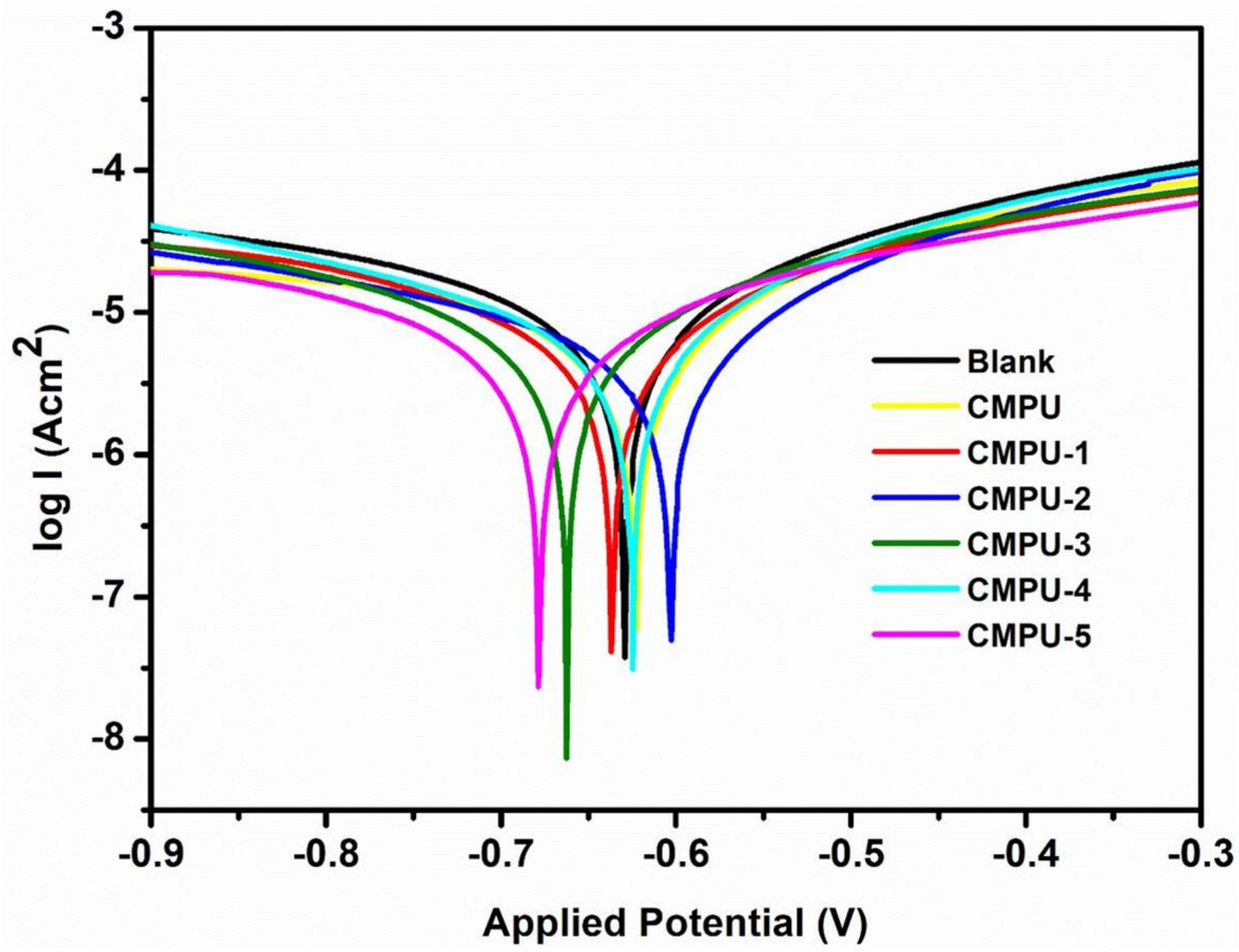

Figure 8

Tafel plot of CMPU, CMPU-1, CMPU-2, CMPU-3, CMPU-4, and CMPU-5 coated samples in aq. $3.5 \% \mathrm{NaCl}$ medium 


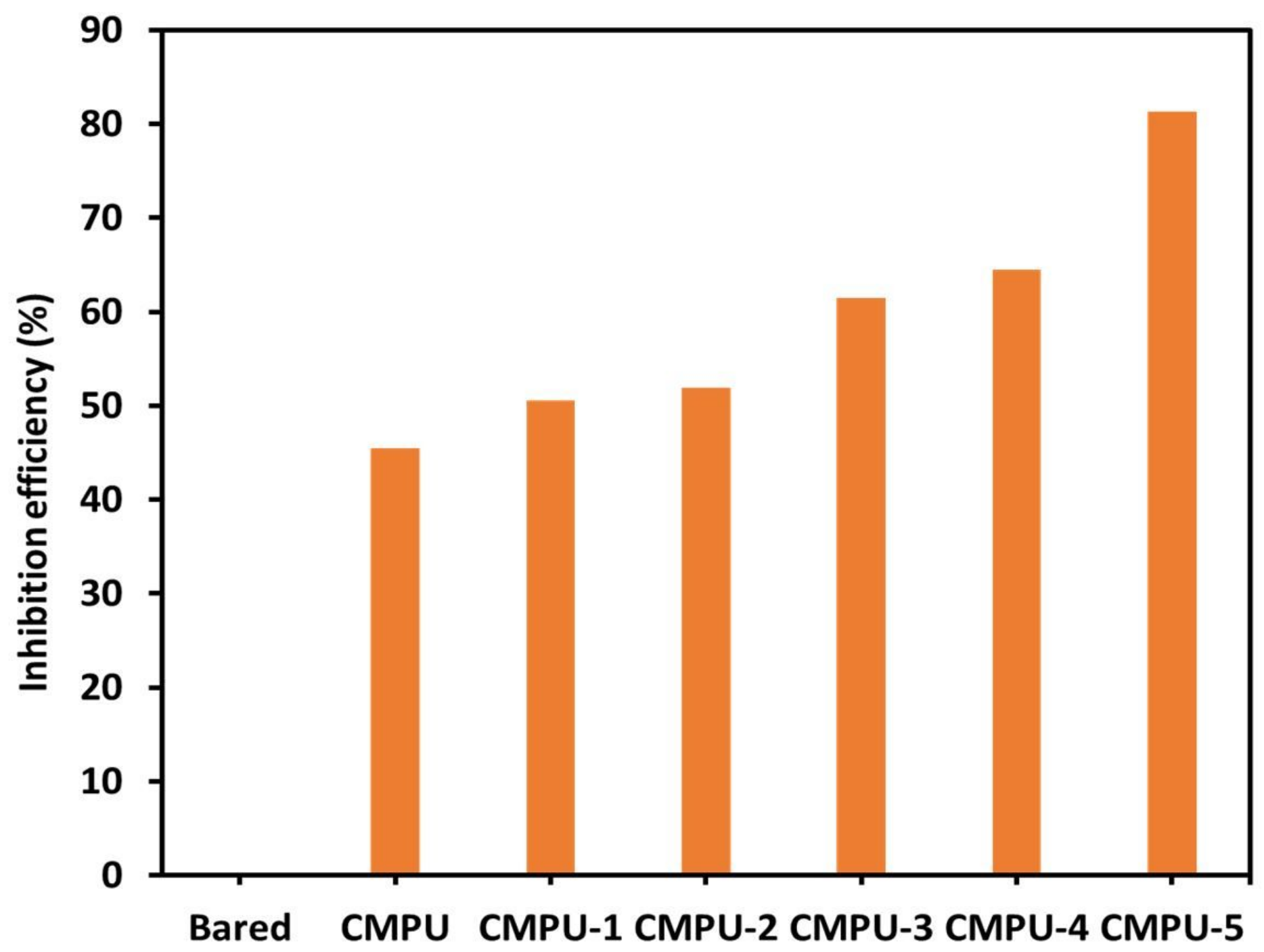

Figure 9

Inhibition efficiency of bare, CMPU, CMPU-1, CMPU-2, CMPU-3, CMPU-4, and CMPU-5 coated samples tested against aq. $3.5 \% \mathrm{NaCl}$ solution 


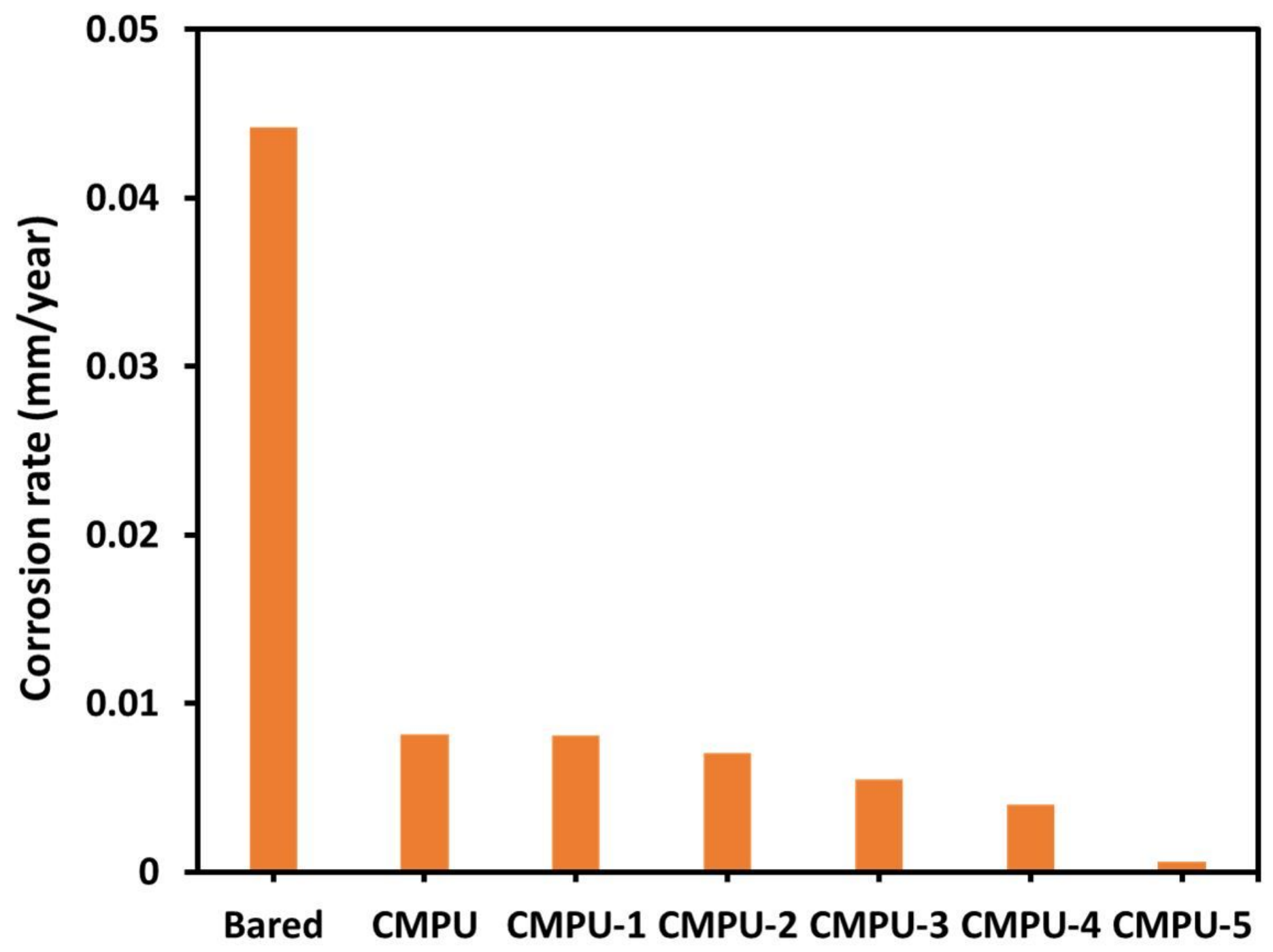

Figure 10

Corrosion rate of bare, CMPU, CMPU-1, CMPU-2, CMPU-3, CMPU-4, and CMPU-5 coated samples tested against aq. $3.5 \% \mathrm{NaCl}$ medium 


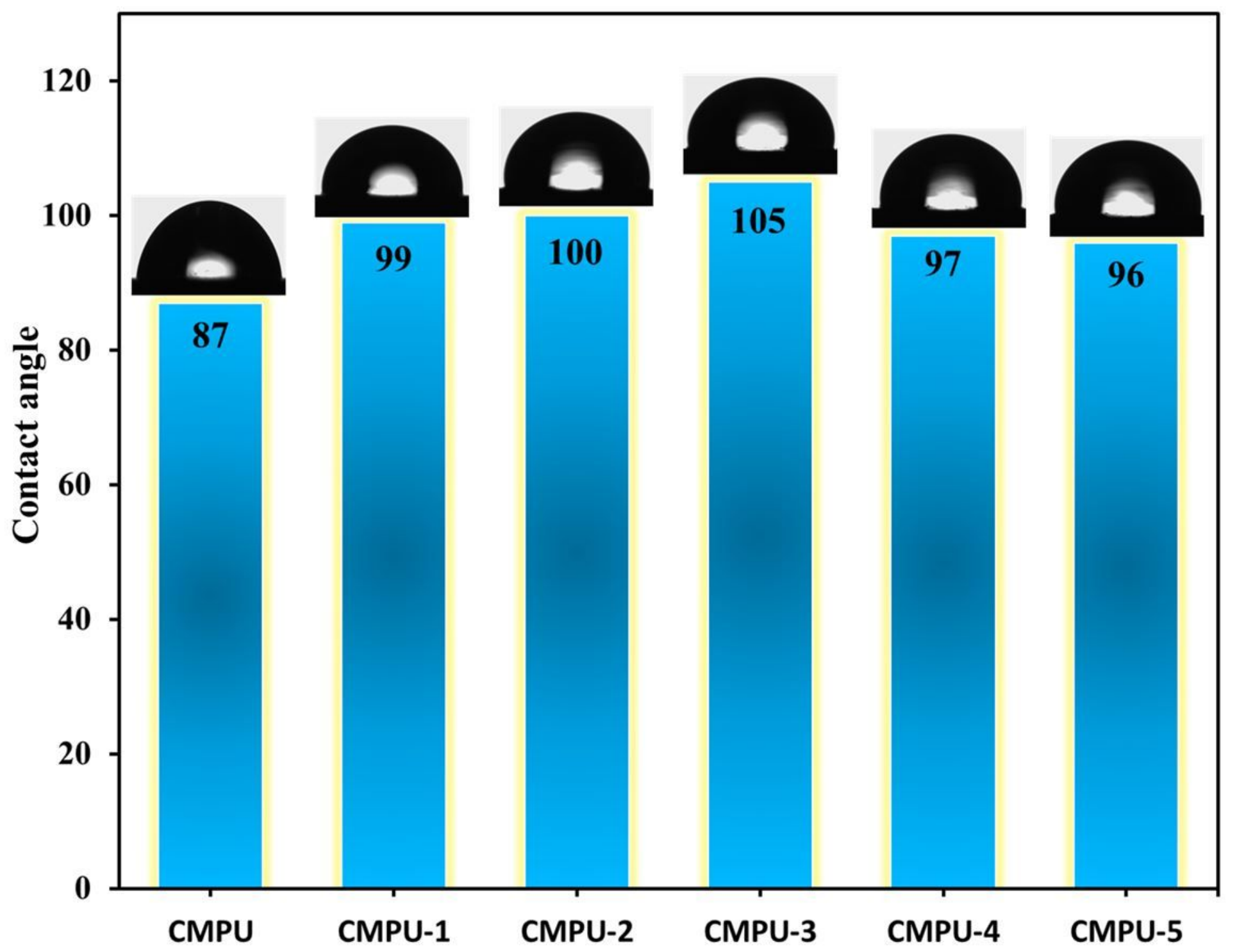

Figure 11

Contact angle of CMPU, CMPU-1, CMPU-2, CMPU-3, CMPU-4, and CMPU-5 coated samples 


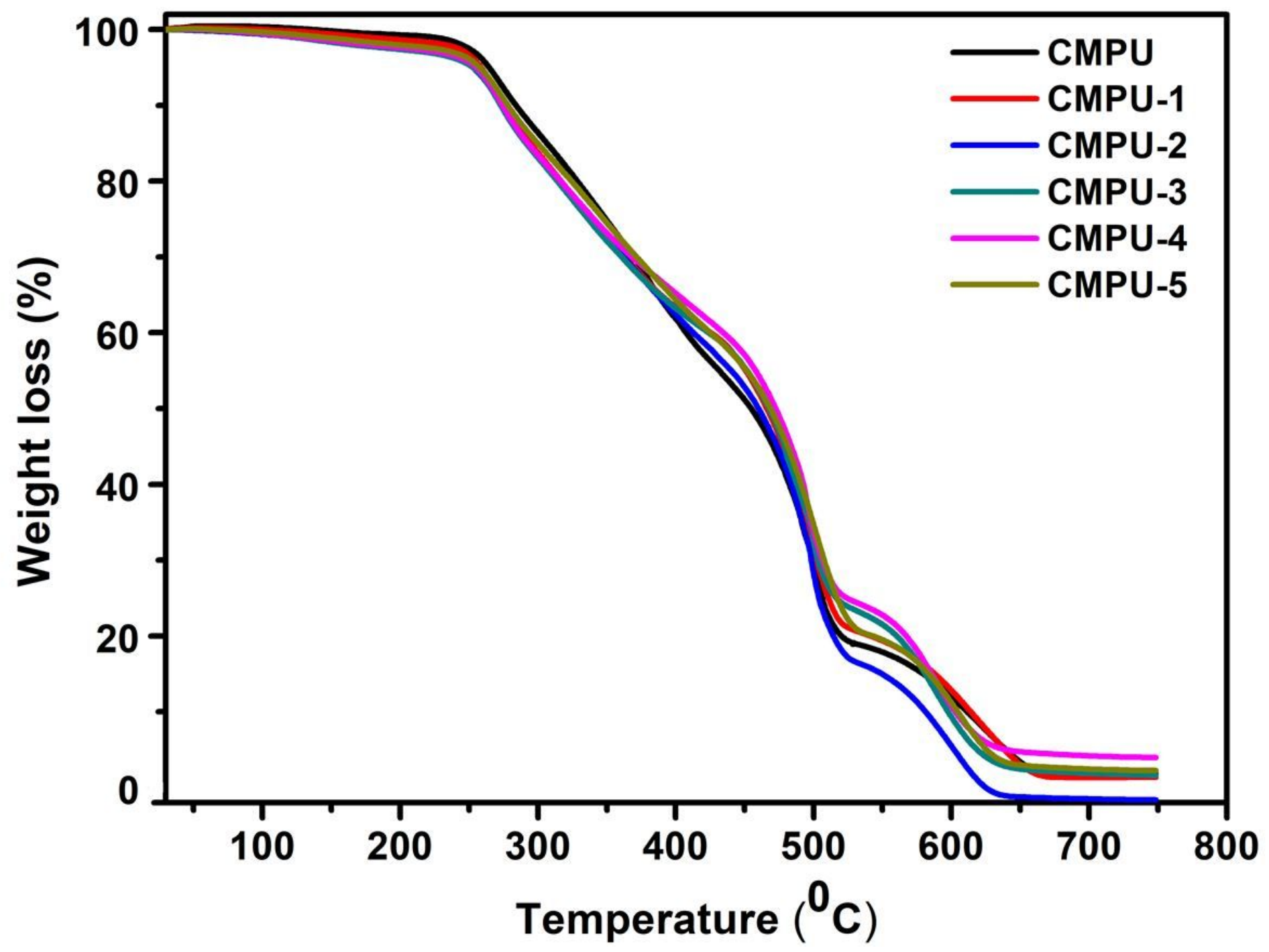

Figure 12

Thermogravimetric curves of CMPU, CMPU-1, CMPU-2, CMPU-3, CMPU-4, and CMPU-5 coated sample. 


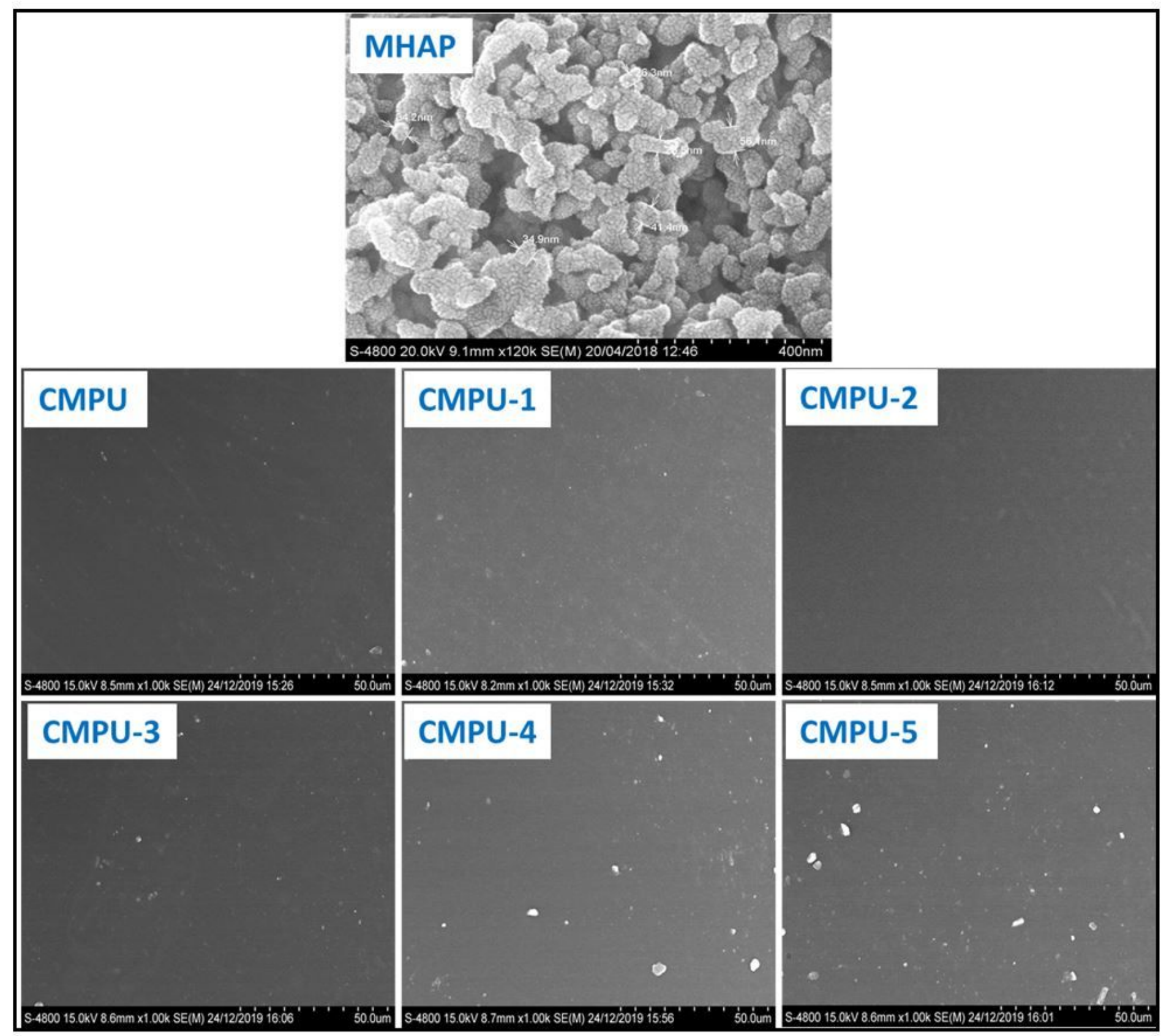

Figure 13

SEM images of MHAP, CMPU, CMPU-1, CMPU-2, CMPU-3, CMPU-4, and CMPU-5 coated samples.

\section{Supplementary Files}

This is a list of supplementary files associated with this preprint. Click to download.

- scheme1.jpg

- scheme2.jpg

- graphicsabstract.jpg 